\title{
Information in Civil Societies - a multi-faceted approach
}

This issue of the Cosmopolitan Civil Societies Journal addresses many of our contemporary issues around information and knowledge management in civil societies. It takes a holistic view of information and knowledge management by touching upon all facets of its expression in our lives -- the personal, the professional, the social, the negotiated, and the public.

The articles deal with aspects of information and knowledge that range from the personal, private and experiential 'knowledges' we value and trust, to how we make sense of our work and our actions using our knowledge, and share information and knowledge in social spaces and in organisations, and how governments encourage the processes of democracy through access to public sector information. A key theme is how knowledge can become part of everyday culture, from the understandings of the iconic Shakespeare to the use of information and data produced by governments or generated through the use of social media in online civil society. The issue of barriers to the spread of scholarly knowledge, which can prevent certain types of knowledge from becoming part of everyday culture, is also raised.

The articles arise from challenges which form the research agenda for the Information and Knowledge in Civil Societies group within the Cosmopolitan Civil Societies Research Centre. These challenges include how are information and data used, shared and re-used in the context of specific communities, cultures and practices, how contexts can influence the process of a cycle of knowledge creation and how do specific communities create and manage knowledge?

Hilary Yerbury’s Revaluing Women's Knowledge calls for a fresh look at women's participation in scholarship and contribution to civil societies by proposing new ways for women to tap into their traditional knowledges and networks using contemporary modes of the information commons such as open access journals that are afforded by digital media.

\section{Michael Olsson’s Making Sense of Shakespeare: a Cultural Icon for Contemporary}

Audiences uses an empirical approach through interviews to argue that the performance of Shakespeare involves the operationalisation of several modes and levels of information, 
understandings, and knowledge that ranges from the epistemic to the historical, cultural, national and political by drawing on information arising from discourses and knowledges that make personal and professional sense to the theatre professionals.

\section{Bhuva Narayan's From Everyday Information Behaviours to Clickable Solidarity in a Place} Called Social Media covers a range of ways in which we conceive of and use social media technologies in our networked information society and how this new form of digital media is affecting information flows in civil society. It does so by using spatial metaphors and theories that help compare and contrast our real world with the virtual worlds of social media.

Dean Leith's Representation of the Concept of Trust in LIS Literature explores the concept of trust and the role it plays in knowledge sharing within and between organisations. It does so by examining the several facets of trust such as faith, truth, power, and authority through various theoretical lenses, for trust is an important aspect of civil society and trust in shared information is the glue that holds it together.

Maureen Henninger's The Value and Challenges of Public Sector Information explains the opportunities and risks to civil society posed by new data-analytic technologies that help both governments and commercial organisations easily access not just the content of public sector information but also aid the discovery of new and unintended information within this information store through discerning the information patterns using metadata and other markers. This is a very important and timely topic of discussion that relates to all the other articles in this issue for it affects how and what we intentionally and unintentionally reveal about our personal and private information. Public sector information is necessary for civil societies but public information that is publicised or used in ways they were not originally intended can affect both our personal and professional lives and also the organisations we place our trust in.

Other scholars are confronting similar challenges in their work on information and knowledge in civil society. We hope that these articles from our research group will encourage others to submit their efforts to respond to these challenges to the Cosmopolitan Civil Societies Journal.

Bhuva Narayan

Sydney, November 2013 